\title{
Theoretical thinking of group cooperative learning model and its implications for college English teaching
}

\author{
Shuti Yu \\ School of Management, Changchun University of Chinese Medicine, Boshuo Rd, Changchun, China \\ shutiyu@hotmail.com
}

Keywords: Group cooperative learning, College English teaching.

\begin{abstract}
This paper has introduced the meaning and characteristics of group cooperative learning mode; summarized the research progress of group cooperative learning model at home and abroad; analyzed the necessity of combining it with college English teaching with the deep insight, and systematically interpreted the formative and theoretical basis of this model. Finally, the development direction and pedagogical implications of the group cooperative learning model in College English teaching in the future are put forward. Group cooperative learning, as a new educational theory, uses the interaction of various dynamic factors in teaching to promote students' learning, and takes group performance as the evaluation standard to accomplish teaching objectives together.
\end{abstract}

\section{Introduction of group cooperative learning model}

\subsection{The meaning and characteristics of group cooperative learning Mode}

Group cooperative learning is a kind of learning with student-student interaction as the main feature, some domestic scholars define it as "cooperative learning group is a teaching strategy system that aims to promote students mutual cooperation in heterogeneous groups, to reach a common goal, and makes the overall team score as a reward basis" ${ }^{11]}$. The group cooperative learning model itself has the following characteristics:

\subsubsection{Interdependent cooperativeness}

With the setting of common goals as guarantee, the group cooperative learning promotes the mutual aid and cooperation of learning. There are one or more goals between students and students. In order to achieve the common goal, the members play different roles with complementary and internal relevance, and undertake different tasks. The cooperation and tacit understanding of the parties involved in the cooperation determine the success or failure of the cooperation. In the same situation, with common goals, common competing objects, common ideological tendencies, etc., so many common things, determines the inseparable interdependent relation between members.

\subsubsection{Democratic equality}

Before learning new knowledge, students have different life, different learning experience and personality traits, and this diversity makes them not have the high and low points in cooperative learning, no status differences, but a relationship of equality. In order to achieve a common goal, team members need to play their respective advantages, complement from each other, make full use of existing resources, optimize the allocation, better cooperate with one another, to optimize team cooperation. Common goal orientation makes group cooperation democratic and equal.

\subsubsection{Communicative property}

Traditional education regards learning process as the process of mastering knowledge. The 
progress and development of students is the knowledge that is mastered. The speed of progress and development depends on the efficiency of mastering knowledge. In group cooperative learning, students change the original monologue learning, and replaced it with a learning form full of dialogue and communication. The exchange and interaction among members of the group will restore the learning process into a more life oriented process, and communicate knowledge as a kind of communicative thought, which can enlighten each other.

\subsubsection{Generative property}

Jaspers (Jaspers, 1883) proposed that education is generation, the so-called education, but is the exchange activities of body and soul between people, including teaching of the intellectual content, comprehension of life connotation, norms of volitional behaviour, and through the culture transferring function, hands cultural heritage over to the younger generation, makes them free to generate, and inspires their free nature ${ }^{[2]}$. The process of group cooperation itself is the process of participation and interaction, and the teaching process should not be carried out step by step according to the teachers' preset links. In group cooperative learning, different students' individual ideological communication, mutual assistance and cooperation may produce more meaningful and unexpected new curriculum resources, but can promote students' learning and growth. Through the cooperative way, in addition to learning classroom knowledge, students can improve their psychological quality, such as learning to be tolerant and to appreciate the strengths of others.

\subsubsection{Sociality}

Compared with the monologue learning, the way of group cooperation is closer to the actual state of life, students need to face competition and cooperation, listening, self-expression and interpersonal interaction, and need to face failure, conflict, contradiction and so on. Cooperative learning helps the students to learn tolerance, understanding, mutual help, and contributes to improve students' work skills, communication skills, then it also has an important role in promoting the socialization of students and important significance for the development of students' psychological quality.

\subsection{Analysis of the necessity of applying group cooperative learning model to college English teaching}

The representative figure of Information processing theory (Anderson, 1976) believed that learning activity itself is that the individual interacts with external resources through information processing, then keep information and organization for the use of forming corresponding information and organization and in case for extraction and use. Through this process, people can acquire two different kinds of knowledge, namely declarative knowledge and procedural knowledge $^{[3]}$. In the process of learning English, declarative knowledge mainly includes vocabulary, grammatical structure, fixed usage and internalization of special rules, and belongs to the basic category of basic English knowledge, a kind of type of knowledge "what is it?". Procedural knowledge is a kind of type of knowledge "how to do?" , which pays attention to how to do? This type of knowledge acquisition depends on a declarative knowledge base, but focuses on developing students' knowledge for comprehensive ability of using English, which should belong to the category of college English learning, so the university should pay more attention to the cultivation of comprehensive application ability.

Since the college English education and teaching should give full consideration to the development and improvement of students' English integrated and applied ability, it is necessary to re-examine whether the current teaching concept, mode and the current situation of the concrete implementation method is matching with this basic goal. At present, the most popular college English teaching paradigm is mainly based on lecturing. Teachers become "masters" of teaching activities, who complete the teaching tasks according to the curriculum plan. The goal of teaching is basically the same as the previous training goal of high school, and still focuses on the simple teaching of declarative knowledge. However, the formation of English integrated and applied ability can only be achieved through a great deal of practice, exercise and correct feedback. The teaching 
method of lecturing deprives practical application opportunities of students in class, and still stays at the level of consolidating and perfecting the basic knowledge. Therefore, the model of college English teaching needs to be innovated to meet the students' English learning needs.

The teaching model of group cooperative learning can solve the above practical problems well. First of all, the group cooperative learning model affirms the main position of the students in learning activities, and the students are the real "masters" of teaching activities. According to students' prior knowledge foundation, we should create the teaching conditions with personality, strong operability, rich practice opportunities, and guarantee everyone has the opportunity to practice English integrated and applied ability more than once in the course. Secondly, we should stimulate students' learning motivation. The ultimate goal of English learning is to improve and improve the ability to use English comprehensively. Communicative property and instrumentality are essential attributes of English learning. Group cooperative learning can fully mobilize the enthusiasm of students to learn, and each member's individual success accumulates the success of the whole group. During the learning process, each team member will work together to solve difficulties, effectively grow in practice, and experience the difficulties and joy of teamwork(team work).It not only enhances the emotional connection between students, but also improves the understanding and love of the meaning of English skills learning.

\section{Theoretical thinking and education revelation}

As a kind of new education theory, Group cooperative learning uses the interaction of various dynamic factors in teaching to promote students' learning, and takes group performance as the evaluation standard to accomplish teaching objectives together. It is a kind of compound activity, and its theoretical basis also has compound characteristic.

\subsection{Constructivism theory}

Constructivism theory emphasizes that the learning process itself is the process that learners give meaning to what they have learned. Learning is active construction, not passive acceptance. On the basis of the existing cognitive structure, knowledge, experience and learning strategies, the learners actively process the new knowledge information according to the assigned learning materials in a certain context. According to Piaget (Piaget, 1896), the individual integrates the new learning knowledge into his own knowledge structure by assimilating and complying with two different adjustment ways ${ }^{[4]}$. The existing knowledge and experience of learners are the basis of learning, and the meaning will be constructed through the repeated exploration, connection and two-way interaction between the old and new knowledge. Therefore, learning is not only the transfer of new knowledge from outside to inside, but also the process of constructing knowledge and experience actively for learners. In this process, sue to the learners' different personal experience. the constructing way also varies from person to person. Therefore, even in the same learning situations, different students will obtain different meaning or interpretation with accepting the same new information, so as to obtain different learning effects.

According to the viewpoint of constructivism theory, in College English teaching, there is a kind of cooperative and interdependentrelationship between teachers and students and students. Teachers need to organize and guide students to discuss and exchange, at the same time, they should create the corresponding situation for students, advocate joint participation, play the subject consciousness of initiative construction for students in the learning process, so as to improve the learning effect. Group cooperative learning is a process that the group members negotiate and carry conversation with the learning situation provided by teachers, and conduct meaningful and positive construction through the students' independent activities. Such a teaching model can help college students learn English and meet the needs of students.

\subsection{Humanism theory}

Humanism emphasizes respect. Give students the respect they deserve as a social individual, and pay attention to their wishes, emotions and opinions. Humanism believes that everyone has the 
ability of self-education, and thinks that the learning process itself is the process of making full use of the self-potential and constantly improving the personality. Accordingly, the advocates of humanism have created a "topic centred classroom discussion model", developed classroom models and free learning environment models. Group cooperative learning is based on the criticism and inheritance of humanistic learning theory. It is neither excessive indulgence nor excessive control; it not only advocates the leading role of teachers, but also respects the dominant position of students.

College English learning is not only the consolidation and improvement of early learning, but also should enhance the training of English applied skills, practical communication ability to highlight the status. However, the traditional teaching methods are mainly based on the teaching style, and the students do not have much opportunity to exercise actual English integrated and applied ability in class. .The test-oriented training model must cultivate more students with "dumb English" . They can do exercise and read, buy can't speak or get it. This kind of education is not education that students want, in the learning process they show no interest, weariness, lack of input and so on. However, the group cooperative learning model can make every student actively participate in learning, and make students of each group cooperate to solve the corresponding problems through reasonable teaching design. It truly reflects the guiding principle of respecting students' needs and caring for students' development.

\subsection{Recent development zone theory}

Vygotsky, the former Soviet Union famous psychologist (Vygotsky, 1978) pointed out that the psychological development of children has two levels: the first is the actual development level, namely the level of psychological development shown in the process of solving problems independently of children; the second is the potential development level, which refers to the psychological development shown by children in solving the problem with the help of others. The area between the level of children's actual development and potential development is called the "nearest development area". It is in the dynamic interaction process between the two level, children's psychological levels develop constantly from junior to senior ${ }^{[5]}$.

The nearest development area is not only reflected in the teaching activities between teachers and students, but also in the cooperation with the stronger partners. In English teaching, through discussion and debate between team members, consultation, coordination and so on with the members of the group, many problems of the errors in the grammatical structures use and English applied abilities are exposed. And through group cooperation, mutual evaluation and other means, the relevant issues can be effectively resolved, students will also reach a level of understanding with higher quality, and the comprehensive potential of English application can be played.

\subsection{Motivation theory}

Motivation theory is based more on students' own interests. From the point of view of motivation theory, the cooperative target structure creates a situation where individual goals can be reached only by achieving group goals. Therefore, to achieve personal goals, team members must assist partner to do any help to team success, and, more important is to encourage companions make the greatest efforts to fully mobilize and adjust motivation and emotional arousal level in the process of English learning, on order to improve learning efficiency. Under the cooperative goal structure, group members work together for a common goal, and their learning effort contributes to the success of the partner.

Learning motivation is produced with the aid of the interpersonal communication process, whose essence embodies a kind of positive and dependent relationship established by interpersonal interaction, and the most effective means of stimulating motivation is to establish a "community of interests". In English teaching, adopting the model of group cooperative learning is bound to make students feel the support and encouragement of peers, and learning becomes a growth process in a positive environment.

In addition to the above several representative theories, cooperative learning group also draws on many other theories, such as from the group dynamics theory, in heterogeneous groups, students with different intellectual levels, knowledge structures, cognitive styles can complement each other, 
inspire and complement each other, so as to achieve mutual collision thinking and create new thought; group cooperative learning is conducive to the generation of students' self-esteem, selfrespect and feelings, so that students will feel confident and improve self-efficacy; the recognition and praise of teachers and classmates can help to the satisfaction of the esteem needs, thus strengthening the learning motivation and improving the academic performance. The representative figure of the Gestalt school Lewin (Lewin, 1890)found that in cooperative groups, individuals with strong motivation can encourage understand each other, and promote the smooth information communication between individuals, and the work efficiency of cooperative groups is obviously higher in non cooperative group ${ }^{[6]}$.In addition, there are social cohesion theory, teaching technology theory, contact theory, research learning and so on. Although many theoretical basis of cooperative learning group are scattered, there is not a contradiction between the various theories, and they complement each other, together forming a powerful theoretical foundation of cooperative learning group, more creating a new development direction of college English teaching in the future.

Group cooperative learning has created a new field of modern teaching research, so that every student can learn research, so that every student can learn to cooperate, but also enrich the teaching interaction theory. Group cooperative learning is better than independent learning situation, in complex tasks, cooperative learning promotes the interactive quality of students, promote students' learning ability, learning difficulties and participation of students was obviously improved, the innovation of teaching organization form, highlighting the affective function. Group cooperative learning can produce good result in promoting students' interaction, improving students' awareness and level of participation, solving complex problems and promoting the learning ability of students with learning difficulties. In order to cultivate all-round development of people, promote the group cooperative learning model is very important.

\section{References}

[1] Maganioti, A.E., Chrissanthi, H.D., Charalabos, P.C., Andreas, R.D., George, P.N. and Christos, C.N. (2010) Cointegration of Event-Related Potential (ERP) Signals in Experiments with Different Electromagnetic Field (EMF) Conditions. Health, 2, 400-406.

[2] Bootorabi, F., Haapasalo, J., Smith, E., Haapasalo, H. and Parkkila, S. (2011) Carbonic Anhydrase VII-A Potential Prognostic Marker in Gliomas. Health, 3, 6-12.

[3]Wang Tan.Cooperative learning: A kind of teaching theory worthy of reference[J].General Education Research,(1994), 2,87-91

[4]Jaspers, Zou Jin.What is education? [M]. Shanghai: Sanlian bookstore, (1991),400-406

[5]Chen Gang. Cognitive mechanism of scientific discovery learning and software modelling of its learning environment[D].Nanjing Normal University,(2008), 1,3-5

[6] Yu Jun. Piaget's epistemological review[D].Jilin University,(2014) 3,6-12

[7] Pang Guobin, Wang Dongling. Theory and practice of cooperative study[M]. Beijing: Kaiming Press Edition,(2003), 7,223-254

[8] Tian Fengjun. Educational Action Research and the Creativity in Foreign Language Teaching[J]. Foreign Language Education,(2003),6,105-110 